\title{
Chronic pain in the spinal cord injured: statistical approach and pharmacological treatment
}

P Fenollosa MD,${ }^{1} \mathrm{~J}$ Pallares MD,${ }^{1} \mathrm{~J}$ Cervera MD,${ }^{2} \mathrm{~F}$ Pelegrin $\mathrm{MD},{ }^{1} \mathrm{~V}$ Inigo $\mathrm{MD},{ }^{2} \mathrm{M}$ Giner, ${ }^{2} \mathrm{~V}$ Forner MD, ${ }^{2}$

${ }^{1}$ Pain Unit, Department of Aneasthesiology, ${ }^{2}$ Spinal Cord Injury Unit, Department of Physical Medicine and Rehabilitation, University Hospital 'La Fe', Avda Campanar 21, 46009 Valencia, Spain.

We include in this article the results of a postal inquiry into chronic pain in SCI patients in Valencia (Spain), and our experience with their management. A mailed questionaire including lesion and chronic pain data was sent to all of the 380 SCI patients who live in the region of Valencia. We received 202 answers, with 145 questionaires being accurately answered and these were analysed for this study. The results show that chronic pain (that is, lasting more than 6 months) is very common $(65.5 . \%)$.

The most frequent type was deafferentation pain (phantom pain), described as burning or a painful numbness.

Since 1988 we have been treating a sample of 33 patients suffering from resistant pain according to the following therapies:

1 amitryptiline + clonazepan + NSAID (nonsteroidal antiinflammatory drugs);

2 amitryptiline + clonazepan +5 -OH-tryptophane + TENS (transcutaneous electrical nerve stimulation);

3 amitryptiline + clonazepan + SCS (spinal cord stimulation);

4 morphine, by continuous intrathecal infusion.

After almost 4 years using these therapies we can affirm that the results regarding analgesia reached $80 \%$ in all cases, and that morphine used by intrathecal route is very safe and useful in selected patients.

Keywords: chronic pain; spinal cord injury; deafferentation pain; spinal morphine; spinal cord stimulation.

\section{Introduction}

Chronic pain after spinal cord injury (SCI) has been reported to occur in $40-100 \%$ of patients. ${ }^{1-3}$ The aetiology and clinical presentation has focused on different aspects and many classifications have been proposed. ${ }^{4-7}$ Because of the difficulty of successful management, a wide variety of treatments have been used with variable results. ${ }^{8}$

In this study we have summarised the results from a questionnaire on pain accurately answered by 145 SCI patients. We also report on our pharmacological approach to the treatment of these patients.

\section{Material and methods}

A mailed questionnaire requesting data about SCI and pain was sent to all 380 members of the national association of SCI patients living in the region of Valencia. We received 202 answers (53\%); 57 questionnaires with defects, failures or controversy in the answers were rejected. The remaining 145 questionnaires were accurately completed and were included in this study.

Different qualities of pain were suggested in the questionnaire (burning, sharp, aching, throbbing, shooting, etc), along with a request to provide a diagram and shade in the painful areas, questions about 
the body positions that made the pain worse, and both the Lattinen and visual analogue scale test with instructions for accurate answers.

Our therapeutic experience is based on the management of the 33 patients with chronic pain who have been sent to the pain unit by the rehabilitation department in the last 4 years. The sample is described in Table I.

In 1987 we proposed a management approach based on three steps. For those patients who failed to obtain satisfactory analgesia, we added a new therapeutic step: the continuous intrathecal perfusion of morphine (Table II)..$^{9.10}$

Although there is no general agreement on the criteria for choosing intrathecal opioids, we chose this way based on the previous literature and on our own experience in cancer pain. ${ }^{11-14}$ In addition, the new internal pumps programmed by telemetry simplify the use of the intrathecal route. Finally, the use of intrathecal morphine seems to benefit spasticity, as has been reported in other studies. ${ }^{15.16}$

The treatment was given according to our 'step programme'. When the therapy was not successful the patients passed to the next

Table I Information concerning patients*

\begin{tabular}{lcc}
\hline & $\begin{array}{c}\text { No. of } \\
\text { patients }\end{array}$ & $\%$ \\
\hline Sex & 23 & 69.7 \\
$\quad$ Male & 10 & 30.3 \\
$\quad$ Female & 14 & 42.4 \\
Level of lesion & 4 & 12.1 \\
$\quad$ Cervical & 6 & 18.1 \\
$\quad$ Upper thoracic & 9 & 27.3 \\
$\quad$ Lower thoracic & & \\
$\quad$ Lumbar & 16 & 48.5 \\
Degree of lesion & 17 & 51.5 \\
Complete & 8 & 24.2 \\
Incomplete & 20 & 60.5 \\
Type of pain & 5 & 15.2 \\
$\quad$ Radicular & & \\
$\quad$ Deafferentation & 10 & 30.3 \\
$\quad$ Musculoskeletal & 23 & 69.7 \\
Aetiology of the spinal lesion & \\
$\quad$ Medical & & \\
$\quad$ Traumatic & & \\
\hline
\end{tabular}

$*$ Average age $=5.3(16-70)$.
Table II Therapeutic stages

1 Amitriptyline + clonazepan + NSAID

2 Amitriptyline + clonazepan $+5-\mathrm{OH}$

Tryptophane + TENS

3 Amitriptyline + clonazepan + spinal cord stimulation

4 Continuous intrathecal infusion of morphine

NSAID $=$ Non steroidal antiinflammatory drugs.

TENS $=$ Transcutaneous electrical nerve stimulation.

stages. The waiting period between each stage ranged from 15 to 90 days, with an average of 35 days.

Regarding the first step, low initial doses of amitryptiline ( $30 \mathrm{mg} /$ day) were given, and were increased to $75 \mathrm{mg} /$ day after an adaptation period of 10 days. Clonazepam was administered in drops for a more convenient dosing, using low doses $(0.6-1.5 \mathrm{mg} / \mathrm{day})$. As an analgesic, we added an antiinflammatory drug, especially for painful musculoskeletal conditions. Patients were always informed about all possible side effects, and were given our telephone number.

Some patients were taking baclofen orally to treat spasticity: this drug was not withdrawn. However, all analgesic drugs were suppressed before starting our therapeutic protocol. Patients with psychiatric disorders were excluded. If good pain control was not achieved and patients asked for more analgesia, we began the second step after a peroid of 35 days. This was focused on neuromodulation, changing the antiinflammatory drug for 5-OH-Tryptophane (300 $\mathrm{mg}$ /day), and adding TENS.

The model of TENS used was a 'Pulsar' (Spembly Medical) which has two channels and four electrodes. We always started with conventional stimulation (rate: $90 \mathrm{~Hz}, \mathrm{PW}$ : $75 \mu \mathrm{s}$, and low amplitude: $10-30 \mathrm{~mA}$ ) to produce a comfortable tingling sensation. Two electrodes were placed at the lower paravertebral dermatome with sensibility, and another two over the painful dermatomes.

If satisfactory pain relief was not obtained, the patients were advised to change 
the device controls in order to try to obtain a better response. A period of stimulation for between 3 and 6 hours daily was recommended according to individual requirements.

If improvement was not obtained after a trial period of 30-40 days and psychological problems were ruled out, the spinal cord stimulation technique was explained to the patient, and was then implanted after a waiting period of $2-3$ months if this treatment was accepted by the patient.

Under local anaesthesia, a tetrapolar electrode was introduced into the posterior epidural space through a Tuohy needle placing it in the central and posterior level of T9-10 to stimulate the lower limbs.

The electrode was connected to a test stimulator and, under fluoroscopy, was manipulated to elicit paraesthesiae in the affected painful area. Using percutaneous extension wires, 1 week of stimulation trial was performed.

If sufficient relief was achieved after the trial of a week, the electrode system was permanently implanted, connecting it subcutaneously to a generator (Itrel II) in an abdominal pocket under local anaesthesia. The current parameters were modulated until comfortable paraesthesiae were felt.

The results of the study have been assessed using the Lattinen test, the visual analogue scale and the subjective opinions of family members about changes in the patients' quality of life. The Lattinen test is used as a rule in the first evaluation of all patients in our pain unit. It consists of five groups of easy questions on pain, with four possible answers in each one. Every group is scored from 0 to 4 points. The total score is obtained by adding the score of each selected word in the five groups of questions (maximum 20 points). The test provides information about the intensity of pain, frequency, analgesics intake, disability, and sleep (Table III). ${ }^{17}$

The patients who were chosen for the intrathecal infusion were previously submitted to a three doses test of intrathecal morphine (one dose every 48 hours) in order to evaluate any possible side effects and the degree of analgesia achieved. We always started with $0.6 \mathrm{mg}$ and continued
Table III The Lattinen test

\begin{tabular}{lll}
\hline & No pain & 0 \\
(A) & Mild & 1 \\
Subjective & Uncomfortable & 2 \\
intensity & Severe & 3 \\
& Unbearable & 4 \\
(B) & Never & 0 \\
Frequency & Rare & 1 \\
& Frequent & 2 \\
& Very frequent & 3 \\
(C) & Continuous & 4 \\
Analgesics & None & 0 \\
intake & Occasional & 1 \\
& Moderate & 2 \\
High consumption & 3 \\
(D) & Too much & 4 \\
Disability & None & 0 \\
due to pain & Slight & 1 \\
& Moderate & 2 \\
& Necessary aid & 3 \\
(E) & Total & 4 \\
Sleep & Normal & 0 \\
& Sometimes awake & 1 \\
& Many times awake & 2 \\
& Insomnia & 3 \\
\hline
\end{tabular}

Choose one word in each group; score 0-20.

with $0.3-1 \mathrm{mg}$ according to the response obtained. We consider it to be of great importance to inform the patient of all possible side effects of intrathecal morphine.

After assessing the results of the three doses test, the implant of an internal infusion pump ('SynchroMed B611 H', Medtronic Inc) was considered in patients who achieved a degree of analgesia of over $50 \%$ and lasting at least 12 hours. A continuous infusion using $0.6 \mathrm{mg} /$ day was started in the implanted patients.

All patients had an initial evaluation of pain severity, with assessment and follow up evaluation at $3,6,12,18,24$ and 36 months after implanting the pump.

\section{Results}

The data obtained from the postal survey are summarised in the tables (Tables IV, V 
Table IV General data (postal survey)

\begin{tabular}{lcc} 
Sex & & \\
Male & 117 & $(80.6 \%)$ \\
Female & 28 & $(19.4 \%)$ \\
Age (yrs) & 37 & \\
$\quad$ Average & $13-70$ & \\
Range & 25.5 \\
\hline
\end{tabular}

Table V Lesion data (postal survey)

\begin{tabular}{lcc}
\cline { 3 - 3 } & $\begin{array}{c}\text { No. of } \\
\text { patients }\end{array}$ & $\%$ \\
\hline $\begin{array}{l}\text { Degree of injury } \\
\quad \text { Complete }\end{array}$ & 83 & 57.2 \\
$\quad$ Incomplete & 62 & 42.7 \\
Aetiology & & \\
$\quad$ Traumatic & 120 & 82.7 \\
$\quad$ Medical & 25 & 17.3 \\
Level of injury & & \\
$\quad$ Cervical & 38 & 26.2 \\
$\quad$ Upper thoracic & 23 & 15.8 \\
$\quad$ Lower thoracic & 67 & 46.2 \\
$\quad$ Lumbar & 17 & 11.7 \\
Spasticity & 94 & 65 \\
\hline
\end{tabular}

and VII). We can summarise our results statistically:

1 Chronic pain in SCI is very frequent $(65.5 \%)$

2 Most of the patients (52\%) described the pain as being continuous, burning or as a painful numbness, with a painless period of time following the lesion. so that we may consider deafferentation pain as being the most common type. Other types of pain described were: 'like electricity' $(9 \%)$, pressure $(7 \%)$ and poorly defined $(32 \%)$.
Table VI Pain data (postal survey)

\begin{tabular}{|c|c|c|}
\hline & $\begin{array}{l}\text { No. of } \\
\text { patients }\end{array}$ & $\%$ \\
\hline $\begin{array}{l}\text { Pain }{ }^{\mathrm{a}} \text { lasting for more than } \\
6 \text { months }\end{array}$ & 95 & 65.5 \\
\hline \multicolumn{3}{|l|}{ Sex } \\
\hline $\begin{array}{l}\text { Males with pain } \\
\text { Females with pain }\end{array}$ & $\begin{array}{l}76 \\
19\end{array}$ & $\begin{array}{l}65 \\
67.8\end{array}$ \\
\hline \multicolumn{3}{|l|}{ Type of lesion } \\
\hline $\begin{array}{l}\text { Complete with pain } \\
\text { Incomplete with pain }\end{array}$ & $\begin{array}{l}55 \\
40\end{array}$ & $\begin{array}{l}67.4 \\
64.5\end{array}$ \\
\hline \multicolumn{3}{|l|}{ Level of lesion and pain } \\
\hline Cervical & & 76.3 \\
\hline Upper thoracic & & 47.8 \\
\hline Lower thoracic & & 65.6 \\
\hline Lumbar & & 76.4 \\
\hline \multicolumn{3}{|l|}{ Age and pain } \\
\hline$<=20$ years & & 40 \\
\hline $21-30$ years & & 46 \\
\hline $31-40$ years & & 60 \\
\hline $41-50$ years & & 68.7 \\
\hline $51-60$ years & & 77.7 \\
\hline$>60$ years & & 71 \\
\hline \multicolumn{3}{|l|}{ Spasticity with pain } \\
\hline SCI with spasticity & & 66 \\
\hline SCI without spasticity & & 53 \\
\hline
\end{tabular}

3 There were no differences related to sex, type of lesion or aetiology of the SCI.

4 Pain was more frequent in patients with cervical and lumbar lesions; those aged over 50 years; and patients with spasticity.

The current distribution of patients according to our management approach is shown in Table VII.

Satisfactory pain relief was noted in six

Table VII Effectiveness of the type of therapy at 3 years

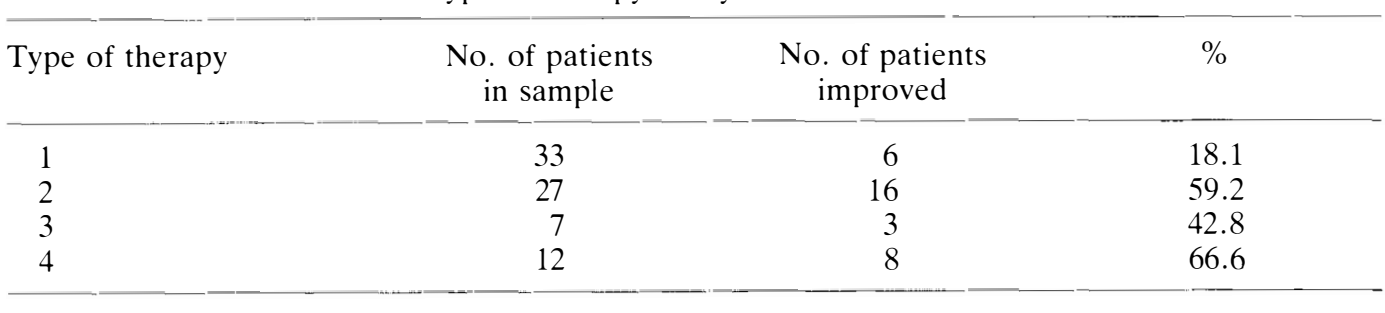


patients who were receiving only oral medication (first step). Sixteen patients improved adding TENS (second step). Seven patients were submitted to spinal cord stimulation, but a good and lasting response was only observed in three of them.

Twelve patients received the intrathecal morphine doses test and a pump was implanted in eight of them with good results.

The results concerning analgesia have been excellent, with pain relief in $80 \%$ on average in all cases; however, some paraesthetic sensation persisted.

We have to point out that the patients who achieved a better response to SCS were those with incomplete lesions and radicular pain. We could not obtain any benefit in patients with complete lesions and deafferentation pain, as has been reported in previous studies. $^{18}$

The doses of intrathecal morphine used in each patient and the degree of tolerance developed after 3 years, are shown in Table VIII.

In our study we also found improvement in spasticity after using intrathecal morphine, according to the results obtained by Erickson and Müller, ${ }^{15.16}$ but it was not scored.

Regarding complications, in two patients it was necessary to replace the intrathecal catheter due to displacement. The patients noted the misplacement because of reappearance of their pain.

\section{Discussion}

Even though a questionnaire letter does not appear to be the best way to obtain medical information, the answers in our protocol were very easy to understand. All patients were advised to review their medical reports to complete the questionnaire. The medical histories were occasionally reviewed. We included the words that our patients use to define the pain in our pain unit. All incomplete questionnaires and those with confused answers were rejected.

Regarding the use of invasive techniques the following questions can be considered.

\section{Pain management}

SCS has been used for pain management since 1967 with differing results. ${ }^{19}$ Melio et $a l^{2(1)}$ reported a survey of 109 patients treated with SCS. The best results were obtained in those with vascular pain, whereas central pain was only improved in $30 \%$ of cases. Cole et al ${ }^{17}$ have recently reported that SCS may be used with good results in patients suffering from central pain only when ascending pathways remain undamaged. Therefore, this technique does not seem to be reliable for patients with complete SCI, as we have observed in our patients.

\section{Why use morphine?}

Although there is no general agreement on the criteria for choosing morphine for deafferentation pain, ${ }^{21-23}$ many authors have reported very good results in the treatment of this type of pain in patient with postherpetic neuralgia, multiple sclerosis, reflex sympathetic dystrophy, or SCI. ${ }^{24-26}$ Moreover, we know that the use of intrathecal morphine is very safe in spite of a prolonged infusion. These results were challenging enough to try the use of intrathecal morphine in patients suffering unbearable pain

Table VIII Continuous intrathecal infusion of morphine tolerance development after 3 years

\begin{tabular}{lclcccc}
\hline Case & Sex & Aetiology & Initial dose & $1 \mathrm{yr}$ & 2 yrs & 3 yrs \\
\hline 1 & $\mathrm{M}$ & Tumour & $0.6 \mathrm{mg} /$ day & Death & - & - \\
2 & $\mathrm{M}$ & Tumour & $0.6 \mathrm{mg} /$ day & 3.0 & Death & - \\
3 & $\mathrm{~F}$ & Syringomyelia & $0.6 \mathrm{mg} /$ day & 0.8 & 3.3 & 6.0 \\
4 & $\mathrm{M}$ & Trauma & $0.6 \mathrm{mg} /$ day & 1.0 & 1.2 & 3.6 \\
5 & $\mathrm{M}$ & Trauma & $0.6 \mathrm{mg} /$ day & 0.9 & 2.5 & 2.8 \\
6 & $\mathrm{~F}$ & Trauma & $0.3 \mathrm{mg} /$ day & 0.3 & 0.5 & 1.6 \\
7 & $\mathrm{~F}$ & Surgical sequel & $0.6 \mathrm{mg} /$ day & 1.0 & 4.0 & 4.6 \\
8 & $\mathrm{M}$ & Trauma & $1.0 \mathrm{mg} /$ day & 3.0 & 3.8 & 5.0 \\
\hline
\end{tabular}


with great limitations in their daily activities.

\section{Tolerance and dependence}

The epidural route has been proved to generate more tolerance than the intrathecal one because of its systemic absorption, thus it should not be used in patients with a long life expectancy. ${ }^{27} \mathrm{~A}$ repetitive bolus of morphine may generate many complications when used over a long period of time (more risk of infections, drug dependence problems if it is used at home, more tolerance, etc) thus the continuous infusion is an important alternative for the management of nonmalignant pain.

The development of tolerance seems to be the most important problem in long term treatment, and some authors refuse to use morphine in patients with chronic, noncancer pain. ${ }^{21.28 .29}$

None of our eight patients developed a significant degree of tolerance after 3 years of treatment using continuous intrathecal perfusion. No withdrawal syndromes were observed. We did not find physical or psychological dependence. These findings were consistent with previous studies. ${ }^{30}$

As we have recently demonstrated, the tolerance is much smaller in patients with nonmalignant chronic pain than in those with oncologic pain, suggesting that the necessity of increasing the dose in patients with malignant disease is more likely due to the tumour growth than to a real tolerance. $^{31}$

Recently, many clinical trials are being focused on diminishing the degree of tolerance using different drugs. Somatostatine, clonidine, encephalines and midazolam have been employed with promising results ${ }^{32.33}$ However, the use of new drugs via the spinal route needs further studies before being used in man. ${ }^{34}$

\section{Is there a risk of respiratory depression?}

Theoretically, using the epidural route, respiratory depression can occur within 2 hours after the administration of morphine, due to blood absorption. With the intrathecal route, this complication may appear between 6 and 12 hours after an injection, probably by ascending the cerebrospinal fluid (CSF) pathways. ${ }^{35}$

The incidence of patients who required naloxone ranged from 0.25 to $0.40 \%$ in a study carried out in Sweden ${ }^{36}$ and from 1.9 to $2.3 \%$ in another review in 74 American institutions ${ }^{37}$ In patients with chronic pain it is really a very rare complication, because the pain strongly stimulates the respiratory centre. ${ }^{38}$

In our experience of over 100 patients treated with intrathecal morphine since 1986 (including malignant pain), only two cases of respiratory depression have been encountered.

Currently, we may observe an increase in the use of intrathecal morphine infusions for treating those patients with refractory, deafferentation pain. ${ }^{39-41}$

\section{Conclusion}

Chronic pain in SCI patients may require a specialised approach since in some cases it is necessary to use aggressive therapies. It is very important to evaluate the type and location of the pain because some patients obtain sufficient relief using physical therapy and NSAIDs.

The spinal route of analgesia is sometimes the best one to provide pain relief. Tolerance is poor and dependence hardly exists.

Therefore, we believe that an intrathecal continuous infusion of morphine is a valuable procedure in the management of chronic pain in SCI patients, when other treatments have failed and a good response to the intrathecal dose test is obtained.

To summarise:

1 It is important to investigate the type and location of the pain.

2 Most patients will experience a sufficient degree of analgesia using the aforementioned drugs plus TENS (stage II).

3 We only recommend the trial of SCS in patients suffering from radicular pain.

4 In those patients with severe, refractory central pain, we have found that a continuous intrathecal infusion of morphine is very helpful. 


\section{References}

1 Nepomuceno C, Fine PR. Richards S et al (1979) Pain in patients with spinal cord injury. Arch Phys Med Rehabil 60: 605-609.

2 Maury M (1978) About pain and its treatment in paraplegics. Paraplegia 15: 349-354.

3 Lami S, Chia JK, Kohli A et al (1985) Chronic pain in spinal cord injury: Comparison between inpatients and outpatients. Arch Phys Med Rehabil 66: 777-778.

4 Guttmann L (1976) Disturbances of sensibility. In: Guttmann L, editor. Spinal Cord Injuries. 2nd ed. Blackwell Scientific Publications, London: 283.

5 Rossier AB, Foo D, Shilito J, Dyro FM (1985) Posttraumatic cervical syringomyelia. Brain 108: 439-461.

6 Melzack R, Loeser JD (9178) Phantom body pain in paraplegics: Evidence for a central pattern generating mechanism' for pain. Pain 4: 195-210.

7 Garcia Fernandez L, Sabate LC. Duarte E et al (1983) Dolores en lesionados medulares. Rehabilitatión 17: 267-272.

8 Davar G, Maciewicz RJ (1989) Deafferentation pain syndromes. In: Portenoy RK. editor. Neurologic Clinics. Pain: Mechanisms and Syndromes. W B Saunders Co. Philadelphia: 289-304.

9 Climent JM. Pallares J, Pallares MJ et al. (1987) Tratamiento del dolor crónico en el lesionado medular. Dolor I.C. \& T. 2: $97-100$.

10) Dimitrijevic MM (1986) Spinal cord stimulation for the control of spasticity in patients with chronic spinal cord injury. Cent Nerv Syst Trauma 3: 129-144/145-152.

11 Coombs D (1986) Management of chronic pain by epidural and intrathecal opioids: Drugs and delivery systems. Int Anesthesiol Clin 24: 59-74.

12 Greenberg HS, Taren J. Ensminger WD, et al (1982) Benefit from and tolerance to continuous intrathecal infusion of morphine for intractable cancer pain. J Neurosurg 57: 360-364.

13 Onofrio B, Yaksh T, Arnold P (1981) Continuous low dose intrathecal morphine administration in the treatment of chronic pain of malignant origin. Mayo Clinic Proc 56: 516-520.

14 Pallares J, Fontestad A. Pallares MJ et al (1989) Administratión epidural de morfina signus bolus versus perfusión contínua mediante bomba ambulatoria y programable. Dolor I.C. \& T 4: 23-27.

15 Erickson D, Blalock JB, Michaelson M et al (1985) Control of spasticity by implantable continuous flow morphine pump. Neurosurgery 16: 215-217.

16 Muller H (1986) Spasticity treatment with spinal morphine or midazolam. Anaesthesist 35: 306-16.

17 Berthold B (1984) Methods of testing pain mechanism in normal man. In: Wall P and Melzack R, editors. Textbook of Pain. Churchill Livingstone, London: 186-194.

18 Cole JD, Illis LS, Sedgwick EM (1991) Intractable central pain in spinal cord injury is not relieved by spinal cord stimulation. Paraplegia 29: 167-172.

19 Shealy CN, Mortimer JT, Reswick JB (1967) Electrical inhibition of pain by stimulation of the dorsal columns: preliminary clinical report. Anesth Analg 46: 489-491.

20 Meglio M, Beatrice C, Rossi GF (1989) Spinal cord stimulation in management of chronic pain. A 9-year experience. J Neurosurg 70: 519-524.

21 Illis LS (1990) Central pain. Much can be offered from a methodical approach. BMJ 300: $1284-1286$.

22 Brian L (1990) Regional analgesia with intraspinal opioids. In: Bonica JJ. editor. The Management of Pain. 2nd ed. Lea \& Febiger, Philadelphia: 1967-1979.

23 Tasker RR (1984) Deafferentation. In: Wall PD. Melzack R, editors. Textbook of Pain. Churchill Livingston, London: 119-133.

24 Albert WA, Maki-Jokela A, Murdoch DM (1985) Intraspinal narcotic analgesia in the treatment of chronic pain. Spine 777-789.

25 Penn RD, Paice JA (1987) Chronic intrathecal morphine for intractable pain. J Neurosurg 67: 182-186.

26 Barolat G, Schwartzman RJ, Aries L (1988) Chronic intrathecal morphine infusion for intractable pain in reflex sympathetic dystrophy. (Abstract). Joint Meeting Abstracts of Canadian Pain Society \& American Pain Society, Toronto, Canada, November 1988 10-13.

27 Arnold C (1989) Intraspinal analgesia: a new route for an old drug. J Neurosci Nurs 21: 30-37.

28 Morgan M (1989) The rational use of intrathecal and extradural opioids. Br J Anaesth 63 165-188.

29 Magora F (1980) Observations of extradural morphine analgesia in various pain conditions. Br J Anaesth 52: $247-257$.

30 Onofrio BM, Yaksh TL (1990) Long-term pain relief produced by intrathecal morphine infusion in 53 patients. J Neurosurg 72: 200-209.

31 Pallarés J, Fenollosa P, Rodriguez A et al (1992) Long-term intrathecal infusion of morphine by internal pumps: a follow-up of four years. (Abstract). 5th International Congress: The Pain Clinic. Jerusalem, Israel, September 14-18, 1992.

32 Coombs DW, Saunders RL, Fratkin JD et al (1986) Continuous intrathecal hydromorphone and clonidine for intractable cancer pain. J Neurosurg 64: 890-894.

33 Moulin D, Max M, Kaiko R et al (1985) Analgesic efficacy of IT d-ala2-d-leu5-enkephalin (DADL) in cancer patients with chronic pain. Pain. 23: 213-221.

34 Yaksh TL, Gaumann DM, Stevens CW (1988) Receptors in the dorsal horn and intrathecal drug 
administration. In: Penn R, editor. Neurological Applications of Implanted Drug Pumps. New York Academy of Sciences, New York: 90-107.

35 Muller A (1986) Administración perimedular de morfínicos. In: Gauthier-Lafaye P, editor. Anestesia Locorregional. 1st ed. Masson SA, Barcelona: 247-273.

36 Gustafsson LL. Schildt B, Jacobsen KJ (1982) Adverse effects of extradural and intrathecal opiates: Reports of a nationwide survey in Sweden. Br J Anaesth 54: 479-487.

37 Mott JM, Eisele JH (1986) A survey of monitoring practices following spinal opiate administration. Anesth Analg $65 \mathrm{~S} 1$

38 Rawal N, Arner S, Gustafsson LL et al (1987) Present state of extradural and intrathecal opioid analgesia in Sweden. Br J Anaesth 59: 791-799.

39 Koulousakis A (1992) Long-term results in spinal cord stimulation and intrathecal opioid therapy of deafferentation pain. (Abstract). 5th International Congress: The Pain Clinic, Jerusalem, Israel, September 14-18, 1992.

40 Rodriguez MJ, Aldaya C, De la Torre MR et al (1992) Treatment of chronic benign pain by means of intrathecal perfusion of morphine. (Abstract). 5th International Congress: The Pain Clinic, Jerusalem, Israel, September 14-18. 1992.

41 Reig E, Gonzalez JR, Garcia A (1992) Neuropathic chronic pain can be relieved with continuous infusion of intrathecal morphine. (Abstract). 5th International Congress: The Pain Clinic, Jerusalem, Israel, September 14-18, 1992. 